\title{
TIPOS DE NARRADOR E NOVAS DISCUSSÕES EM NARRATOLOGIA
}

\author{
Flávia Roberta Menezes de Souza ${ }^{1}$
}

\begin{abstract}
RESUMO
O objetivo desse artigo é discutir conceitos já estabelecidos no campo da narratologia, mais precisamente, os que se referem aos tipos de narrador. Nesse sentido, partiremos das formulações de Gérard Genette (1972), em que ele discute e propõe novos termos para o desenvolvimento de análises de textos narrativos. Esses termos levam em consideração questões que até aquele momento não haviam sido discutidas pelos estudiosos da narrativa, como por exemplo, "os níveis narrativos", as "metadiegeses" e as implicações percebidas pela presença ou ausência do narrador na história. Durante muitos anos, os termos propostos por Genette passaram a subsidiar análises de narrativas, e hoje é sabido, o quanto o campo da narratologia evoluiu, no sentido da problematização dos conceitos dessa área de conhecimento, uma vez que é possível identificá-la não somente auxiliando a leitura de textos literários escritos, mas também de outras formas textuais, como cinema, fotografia, jogos eletrônicos etc. Dessa maneira, serão relacionadas as propostas de Genette e a de Wolf Schmid (2010), que em um estudo mais recente, revisou termos e conceitos desse campo de estudo, abrindo caminhos para novas propostas. Em Narratology: na introduction, Schmid identifica os grandes problemas em torno da nomenclatura que serve aos tipos de narrador, já discutidos antes por Genette. O artigo enfatiza justamente o diálogo entre as duas propostas de organização dos tipos de narrador de Genette e de Schmid.
\end{abstract}

Palavras-chave: Narratologia. Gerard Genette. Wolf Schmid. Tipos de narrador.

\begin{abstract}
The purpose of this article is to discuss concepts already established in the field of narratology, more precisely, those that refer to the types of narrator. In this sense, we will start with the formulations of Gérard Genette (1972), in which he discusses and proposes new terms for the development of narrative texts analysis. These terms take into account questions that have not been discussed by narrative scholars, such as "narrative levels," "metadiegeses," and the implications perceived by the narrator's presence or absence in history. For many years, the terms proposed by Genette began to support analysis of narratives, and it is now known, how much the field of narratology has evolved, in the sense of problematizing the concepts of this area of knowledge, since it is possible to identify not only helping to read written literary texts, but also in other textual forms, such as cinema, photography, electronic games, etc. In this way, the proposals of Genette and Wolf Schmid (2010) will be related, which in a more recent study, revised terms and concepts of this field of study, opening the way for new proposals. In Narratology: in the introduction, Schmid identifies the major problems surrounding the nomenclature that serves the types of narrator discussed earlier by Genette. The article emphasizes precisely the dialogue between the two proposals of organization of the types of narrator of Genette and of Schmid.
\end{abstract}

Keywords: Narratology. Gerard Genette. Wolf Schmid. Types of narrator.

Recebido em: 10/08/2017

Aprovado em: 04/09/2017

\footnotetext{
${ }^{1}$ Doutoranda no Programa de Pós-graduação em Letras (PPGL) da Universidade Federal do Pará. E-mail: flaviamenezes19@hotmail.com
} 


\section{INTRODUÇÃO}

A narratologia subsidiou diversos estudos de obras literárias de caráter narrativo: serviu tanto aos estudos da literatura escrita quanto da literatura oral. Trata-se, hoje, de um campo do conhecimento que contribuiu ao longo dos anos com ferramentas conceituais e teóricas para o desenvolvimento de análises de textos, sobretudo, literários. A publicação do Dicionário de Teoria da Narrativa de Ricardo Reis e Ana Cristina Lopes em 1988, é um exemplo do quanto a narratologia tem desempenhado papel importante, ao fornecer ao estudioso uma série de conceitos que possibilita a descrição técnica de muitos procedimentos já observados em obras, tais como a existência de níveis narrativos, tipos de narrador e etc. Descrever e compreender tais procedimentos, contribuem significativamente para uma visão mais objetiva sobre a construção da obra, e permite estabelecer critérios de investigação quando se pretende trabalhar com mais de um autor, ou ainda quando se pretende estabelecer diálogos entre obras de diferentes épocas e estilos. Em 1988, ao publicar um trabalho de teor prático ao estudioso de narrativas, como é o caso do Dicionário, Carlos Reis e Ana Cristina Lopes reforçaram a ideia da importância que teve a reflexão em torno da narrativa, desde que se desenvolveu um conjunto de teorias com um caráter disciplinar, impulsionado pela Estruturalismo Francês.

No Brasil, dentre muitas publicações específicas sobre os tipos de narrador, destaca-se a leitura de Lígia Chiappini Moraes Leite, com a publicação de O Foco Narrativo. Nesse trabalho, a professora apresenta ao leitor, de forma panorâmica, uma discussão sobre narrativa desde Aristóteles, passando por Henry James, Percy Lubbock, Jean Pouillon, até alcançar os autores do Estruturalismo Francês: Roland Barthes e Tzvetan Todorov. O objetivo dela nesse conhecido trabalho é abordar a tipologia do narrador de Norman Friedman. A autora cita e exemplifica cada um dos tipos: Narrador Onisciente Intruso; Narrador Onisciente Neutro; "Eu" como testemunha; Narrador Protagonista; Onisciência Seletiva Múltipla; Onisciência Seletiva; Modo Dramático e Câmara. Ressalta-se que nesta leitura, não há diferença entre "ponto de vista" e "tipologia de narrador". O fato é que essa abordagem de Lígia Leite tornou-se conhecida e muitas análises de narrativas, sem, no entanto, problematizar determinados aspectos típicos dos romances modernos que devem incluir não só a compreensão do tipo de narrador como a percepção do ponto de vista adotado na narrativa.

É dentro desse contexto que nos interessa discutir alguns problemas de ordem conceitual, uma vez que ao lermos essas publicações posteriores às contribuições dos estruturalistas da década de 60, é possível notar alguns aspectos que podem ser postos em 
diálogo com as recentes contribuições de Wolf Schmid, que não são tão populares em nossa tradição acadêmica. Para isso, partiremos das reflexões de Gérard Genette (2008) sobre o narrador, que não deixa de se inserir em uma discussão maior, que é a relação entre narrativa e discurso.

\section{GÉRARD GENETTE: O DISCURSO E A NARRATIVA}

A narratologia é um campo do conhecimento que se desenvolveu graças a uma consciência linguística voltada sobretudo aos estudos literários - especificamente, à narrativa literária - e que alcançou grande espaço na crítica literária no final da década de 60, com a virada dos estudos estruturalistas. A retomada dos pressupostos formalistas, àquela época recém-descobertos, resgatou a preocupação com a construção de uma ciência da literatura. Ainda que o projeto estruturalista tenha se deparado com as limitações de seu próprio aparato teórico diante da complexidade do objeto que estudava, são inegáveis as contribuições que tanto renovaram a linguagem conceitual dos fenômenos literários os quais careciam de termos que oferecessem maior precisão nos trabalhos e pesquisas em torno da narrativa. Também não se pode desconsiderar que o rigor científico buscado pelos estruturalistas propiciou uma série de publicações que até hoje sobrevivem e subsidiam o estudo da narrativa. Nessa perspectiva, propomos lembrar as provocações contidas no texto Fronteiras da Narrativa, de Gérard Genette, publicado pela primeira vez na revista Comunits $n^{\circ} 8$ que reuniu trabalhos pioneiros sobre narratologia, na linha do estruturalismo.

Nesse texto, após discutir as noções de Aristóteles e Platão sobre o valor da narrativa enquanto representação literária, Genette rebate a ideia dos dois filósofos de que a narrativa possui um caráter inferior por ser menos imitativa, e a coloca em um novo lugar: "mimesis é diegesis" (p. 271). Para reconstituir seu raciocínio de maneira breve, podemos dizer que, para Genette, não era possível continuar colocando a ficção poética na condição de simulacro da realidade, pois o objeto da ficção se reduz por ela a um real fingido e que espera ser representado. Analisando por essa perspectiva, não seria possível alcançar a natureza da narrativa em sua forma particular de representar os acontecimentos, pois a linguagem só pode imitar perfeitamente a linguagem, ou ainda, um discurso só pode imitar ele mesmo. Sendo assim, não existe imitação perfeita, pois o perfeito seria a própria coisa e não a imitação; a única possibilidade de imitação é imperfeita.

Posto o lugar da narrativa como representação literária, e, adentrando cada vez mais no campo que realmente lhe interessa, Genette (2008) questiona-se sobre a possibilidade de se 
distinguir descrição de narração, já que essa ideia, apesar de não pensada pelos filósofos, foi colocada em uma tradição mais recente, sobretudo, escolar. Reflete que, enquanto modo de representação literária, a distinção entre narração e descrição não é tão nítida, nem por conta de uma autonomia de seus fins, nem por uma originalidade de seus meios, para que seja necessário o rompimento da unidade narrativo-descritiva. Para Genette (2008), se existe uma fronteira que separa a descrição da narrativa, é bem uma fronteira interna, que ainda sim se dá de modo indeciso. À noção de narrativa, portanto, pode ser englobada todas as formas de representação literária, considerando a descrição como um de seus modos, ou, mais modestamente, como um de seus aspectos.

A última fronteira da narrativa estabelecida por Genette é a que vai evidenciar as particularidades entre narrativa e discurso. Retomando o ponto de vista de Aristóteles, que não considerava poeta quem não escrevesse uma obra que consistisse em imitação por narrativa ou representação cênica, ficando de fora da noção de literatura representativa a poesia lírica, satírica e didática, Genette (2008) procura questionar o lugar, negligenciado na Poética, de uma vasta quantidade de textos, anunciando a necessidade de se pensar as particularidades entre narrativa e discurso. Exemplifica Genette, "para Aristóteles, e apesar de que usa o mesmo metro que Homero, Empédocles não é um poeta” (p. 277), pois sua obra não consiste em imitação, mas simplesmente em um discurso mantido por ele mesmo e em seu próprio nome.

A necessidade de pensar essa fronteira diz respeito, segundo Genette (2008), à distinção proposta por Emile Benveniste entre narrativa e discurso. Benveniste mostra que certas formas gramaticais, como o pronome eu, que implica de certa forma a existência de tu, os "indicadores" pronominais (certos demonstrativos) ou adverbiais (como aqui, agora, hoje, ontem, amanhã, etc.), e certos tempos do verbo, como o presente, o passado composto ou futuro, encontram-se reservados ao discurso, enquanto que a narrativa em sua forma estrita é marcada pelo emprego exclusivo da terceira pessoa.

Daí chega-se à relação entre objetividade da narrativa e subjetividade do discurso que, como ressalta Genette, é totalmente definida por critérios de ordem linguística. $\mathrm{O}$ subjetivismo do discurso está, por exemplo, presente na referência a um eu, que não se define de nenhum modo como a pessoa que fala. Semelhantemente ocorre com o tempo do modo discursivo, que é por excelência o presente, sem com isso significar que o discurso é enunciado no tempo presente. Inversamente, expõe Genette (2008), a objetividade da narrativa se define pela ausência de toda referência ao narrador, revelando a inexistência dele e até mesmo uma autonomia da própria organização da sucessão dos acontecimentos. 
Somente nesse momento é possível observar a narrativa em seu estado puro, pois o texto não apresenta nenhuma informação que necessite, para ser compreendido, ser relacionado com a sua fonte.

É preciso dizer ainda que as essências da narrativa e do discurso não se encontram em estado puro no texto. Cada texto apresenta em proporções diferentes a primeira e o segundo, embora um e outro se afetem de maneiras diferentes. A inserção de elementos narrativos no plano do discurso não basta para emancipar este último plano, pois eles permanecem com maior frequência ligados à referência do locutor. Por outro lado, o autor situa que qualquer intervenção de elementos discursivos no interior de uma narrativa é percebida como uma infração ao rigor narrativo. O fato é que "a pureza da narrativa é mais fácil de preservar do que a do discurso" (GENETTE, 2008, p. 282) e a explicação de Genette para isso é muito simples:

\footnotetext{
Na verdade, o discurso não tem nenhuma pureza a preservar, pois é o modo "natural" da linguagem, o mais aberto e o mais universal, acolhendo por definição todas as formas; a narrativa, ao contrário, é um modo particular, definido por um certo número de exclusões e de condições restritivas (recusa o presente da primeira pessoa, etc.). O discurso pode "narrar" sem cessar de ser discurso, a narrativa não pode "discorrer" sem sair de si mesma. (GENETTE, 2008, p. 282)
}

O mesmo autor expressa, sobre a comparação entre narração e discurso, como uma relação que atingiu diferentes configurações ao longo dos anos, mas que nunca se resolveu por completo. Com o objetivo de mostrar como essa relação se deu na literatura ao longo dos tempos, ele exemplifica o caso da época clássica, "em um Cervantes, um Scarron, um Fielding", em que o autor-narrador, assumindo o próprio discurso, intervém na narrativa e interpela o leitor num tom de conversação familiar; assim como, no mesmo período, identificam-se procedimentos diferentes: romances cuja responsabilidade do discurso era totalmente transferida a um personagem principal que narrava e comentava ao mesmo tempo os acontecimentos na primeira pessoa. Ainda não podendo se resolver nem a falar em seu próprio nome nem a confiar essa tarefa a um só personagem, o autor reparte o discurso entre diversos atores, seja sob a forma de cartas, como fez frequentemente os romances do século XVIII, seja à maneira mais ágil e sutil de um Joyce ou de um Faulkner, fazendo sucessivamente a narrativa ser assumida pelo discurso interior de seus principais personagens. 


\title{
2. TIPOS DE NARRADOR
}

Gérard Genette (1995), em O Discurso da Narrativa, retomando a questão em torno do discurso e da narrativa, contribui para o estabelecimento de conceitos que, posteriormente, passaram a ser amplamente utilizados em estudos e trabalhos sobre narrativa, narrador heterodiegético e homodiegético em substituição às definições narrador em primeira pessoa, narrador em terceira pessoa, tradicionalmente também conhecidas:

\begin{abstract}
A escolha do romancista não é feita entre duas formas gramaticais, mas entre duas atitudes narrativas (de que as formas gramaticais são apenas uma consequência mecânica): fazer contar a história por uma das personagens, ou por um narrador estranho a essa história. A presença de verbos na primeira pessoa num texto narrativo pode, pois, reenviar para duas situações muito diferentes, que a gramática confunde mas a análise narrativa deve distinguir. (GENETTE, 1195, p.243)
\end{abstract}

Genette estabelece, então, um quadro que determina os tipos de narrador quanto à sua inserção na diegese (história) e ao nível narrativo a que pertence: extradiegéticoheterodiegético; extradiegético-homodiegético; intradiegético-heterodiegético; intradiegéticohomodiegético. (para formatar). Seé clara a compreensão do que seja heterodiegético e homodiegético quando se conhece a superada classificação narrador em primeira pessoa, narrador em terceira pessoa, é possível dizer que as classificações extra- e intradiegético dizem respeito à posição do narrador em relação ao nível narrativo, uma vez que é possível o narrador pertencer ao primeiro nível da narrativa e, posteriormente, dentro da história, outro narrador surgir e "se habilitar" a narrar outra história. Tem-se, assim, uma história dentro da história, e os narradores de ambas encontram-se em níveis diferentes, pois falam de lugares diferentes.

Genette, nesse mesmo trabalho, apresenta uma outra maneira de pensar o narrador, que é a focalização. A focalização diz respeito ao conhecimento que o narrador tem sobre a história em comparação com o conhecimento que o personagem tem. Genette adverte que a focalização "nem sempre se aplica ao conjunto de uma obra, portanto, mas antes a um segmento narrativo determinado, que pode ser muitíssimo breve" (GENETTE, 1995, p. 189). Trata-se de uma questão importante, mas que nesse momento apenas será citada para retomar a tipologia de Friedman apresentada por Lígia Leite que relaciona tipos de narrador e ponto de vista como sendo um fenômeno apenas. Ao apresentarmos a proposta traçada por Wolf Schmid (2010), para uma tipologia de narrador, apontaremos as suas críticas em relação à abordagem que o assunto vem recebendo ao longo dos anos, conforme o quadro a seguir: 
Tabela.1- Critérios estabelecidos por Schmid para uma tipologia de narrador

\begin{tabular}{|c|c|}
\hline Critérios & Tipos de narrador \\
\hline Modo de representação & Explícito-Implícito \\
\hline Status diegético & Diegético - Não diegético \\
\hline Hierarquia & Primário - Secundário - Terciário \\
\hline Grau de marcação & Fortemente marcado - pouco marcado \\
\hline Pessoalidade & Pessoal - impessoal \\
\hline Homogeneidade & Compacto - Difuso \\
\hline Posição avaliativa & Objetivo - Subjetivo \\
\hline Habilidade & Onisciente - Conhecedor Limitado \\
\hline Fixação espacial & Onipresente - Fixo em um espaço específico \\
\hline Acessibilidade à consciência dos & Expressa - Não expressa \\
\hline personagens & Confiável - Não confiável \\
\hline Confiabilidade & \\
\hline
\end{tabular}

Schmid (2010) estabelece onze critérios para se pensar a tipologia do narrador. Quantitativamente, trata-se de um painel mais criterioso, mas o ganho está na distinção entre tipologia e ponto de vista na narrativa. Um narrador não diegético, por exemplo, pode assumir o ponto de vista de um dos personagens para narrar determinada situação e nem por isso ocorre uma mudança de tipos. É o que acontece por exemplo em um dos romances de Dalcídio Jurandir, Os habitantes:

Calou-se com muito embaraço e igual reserva. Calou-se. Calado. Está ouvindo o grito da irmã? A modo que foi ontem, a irmã arranca os três dias da folhinha, vai ao tabocal jogando terra nos bichos de criação: jogar nosso confete, senhoras e cavalheiros. É uma batalha. E aquele repente em que se enfia no velho fraque do pai, a máscara ela mesma fez, a cavalo para o pagode dos Ervedosas, tamanho sábado gordo, no Mutá. Precisou ir atrás dela, escondido da mãe, esta na fiúza que a filha só tinha ido desinflamar um pirralho no retiro com garapa de aninga. Flechou o galope atrás da irmã. Desajuízo dela era mais de contrariação que lhe faziam de não poder pôr o pé na cidade? Só? Estava entra-não-entra no pagode, oculta num mirizal, ali agachou-se, de fraque e máscara. (JURANDIR, 1976, p. 36)

O narrador de Os habitantes não participa da história que conta, mas assume o ponto de vista do personagem ao narrar um episódio envolvendo a irmã desse último. É perceptível isso devido à linguagem usada pelo narrador, impregnada de um sentimento que só poderia pertencer ao personagem: "Desajuízo dela era mais de contrariação que lhe faziam de não pôr o pé na cidade?". Nesse momento, não é a tipologia do narrador que se evidencia mas o ponto de vista assumido por ele na narrativa. Explicar o fenômeno apenas determinando que esse 
narrador é um narrador onisciente é não levar em consideração a complexidade da construção narrativa.

Em Relatos de um certo Oriente de Milton Hatoum, podemos também fazer uma leitura do tipo de narrador que atravessa a obra, segundo a proposta de Schmid: "quando abri os olhos, vi o vulto de uma mulher e o de uma criança. As duas figuras estavam inertes diante de mim, e a claridade indecisa da manhã nublada devolvia os dois corpos ao sono e ao cansaço de uma noite maldormida" (HATOUM, 2017, p.7)

Tem-se um narrador diegético, explícito e bem marcado. Conforme avançamos a leitura, percebemos que cada capítulo é narrado por um personagem diferente. Hakim é um dos mais importante, inclusive, pela quantidade de capítulos que narra. Mas é necessário observar certos aspectos que fazem toda a diferença. A primeira narradora do romance é responsável pela parte inicial do relato, enquanto que os demais personagens têm seus relatos adicionados à narrativa, marcados com aspas. Em outras palavras, há ali sempre a palavra de alguém, de um outro, que narra a partir do seu ponto de vista, exprimindo suas subjetividades: “tive a mesma curiosidade na adolescência, ou até antes: desde sempre. Perguntei várias vezes à minha mãe por que o relógio e, depois de muitas evasivas, ela me pediu que repetisse a frase que eu pronunciava ao olhar para a lua cheia" (HATOUM, 2017, p. 35)

Em Relatos de um certo Oriente, os personagens revezam o papel de narradores do romance, sem, no entanto, haver modificação no tipo de narrador. Essas considerações ajudam a pensar as técnicas narrativas presentes em romances e até mesmo estabelecer comparações entre obras. Podem ajudar a pensar por que determinada obra apresenta uma narrativa em que o tipo de narrador permanece o mesmo do início ao fim. Ou ainda, o que torna estável a presença de determinado tipo de narrador em uma obra? Essas questões ajudam a pensar a construção da narrativa, seus aspectos formais, para posteriormente relacioná-los aos aspectos internos da obra.

\section{REFERÊNCIAS}

GENETTE, Gérard. O discurso da narrativa. Tradução: Fernando Cabral Martins. $3^{\text {a }}$ edição. Lisboa: Veja, 1995.

GENETTE, Gérard. Fronteiras da narrativa. In: Análise Estrutural da narrativa. Tradução: Maria Zélia Barbosa. 5ª edição. Rio de Janeiro: Editora Vozes, 2008.

HATOUM, Milton. Relatos de um certo Oriente. Companhia das Letras: São Paulo, 2017. JURANDIR, Dalcídio. Os habitantes. Artenova: Rio de Janeiro, 1976. 
REIS, Carlos; LOPES, Ana Cristina M. Dicionário de Teoria da Narrativa. São Paulo: Ática, 1988.

SCHMID, Wolfgang. Narratology: an introduction. Berlin/New York: Gruyter, 2010. 